\title{
Reactions of Benzene or Alkylbenzenes with Steam over a Silica-supported Nickel Catalyst*
}

\author{
by Masahiro Saito**, Yoshio Sohda**, Michiaki Tokuno** and Yoshiro Morila**
}

\begin{abstract}
Summary: Benzene-steam and alkylbenzenes-steam reactions over a silica-supported nickel catalyst have been studied under atmospheric pressure in a temperature range of $370 \sim 430^{\circ} \mathrm{C}$.

In the reaction of benzene-steam, the methane yield is lower and the carbon dioxide yield is higher than the estimated value. The reaction is zero order with respect to benzene and approximately first order with respect to steam.

In the reaction of alkylbenzenes-steam, ring breakdown and dealkylation occur at the initial stage of reaction, and the former occurs more easily than the latter at high conversion and at high temperature. The number and the position of the alkyl group on the benzene ring influence the reaction rate and the selectivity.
\end{abstract}

The reaction path of dealkylation is proposed as follows:

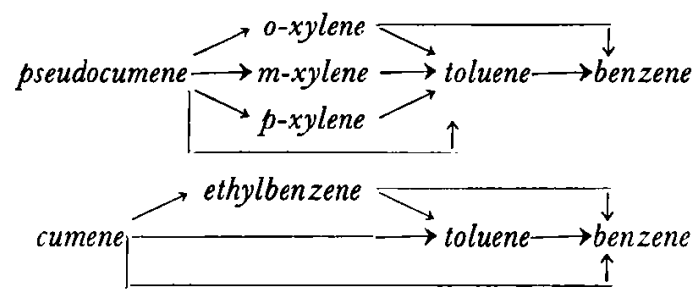

\section{Introduction}

The catalytic reaction of hydrocarbon with steam is important for the production of hydrogen, synthesis gas and town gas. The authors have previously reported the works on olefins-steam and paraffins-steam reactions over a silica-supported nickel catalyst $^{1) \sim 3}$, and this study on aromatics-steam reactions has been carried out as a consecutive one.

Dealkylation and ring breakdown would occur in aromatics-steam reactions. Dealkylation of alkylbenzenes with hydrogen is so significant in industry that much research has been carried out. However, only a few reports on dealkylation with steam have been published.

Maslyanskii et al.4) reported that nickel catalyst is suitable for these reactions, and that $\mathrm{Ni} / \mathrm{Cr}_{2} \mathrm{O}_{3}$ is particularly effective for selective dcalkylation at $350 \sim 430^{\circ} \mathrm{C}$. They also reported the effects of reaction conditions, initial products and rates of reactions.

Ogino et al. ${ }^{5 / 7)}$ reported that $\mathrm{Ni} / \mathrm{BeO}$ is the

* Received December 14, 1971.

** Department of Applied Chemistry, School of Science and Engineering, Waseda University (Nishiokubo, Shinjuku-ku, Tokyo, Japan) most effective catalyst for dealkylation with steam, and they investigated reactivity and reaction path on $\mathrm{Ni} / \mathrm{BeO}$ at $450^{\circ} \mathrm{C}$.

In the present work, the reactions of benzene or alkylbenzenes with steam were carried out over a silica-supported nickel catalyst under atmospheric pressure in a temperature range of $370 \sim 430^{\circ} \mathrm{C}$, and the effects of reaction conditions, rate of each reaction and the reaction path were discussed.

\section{Experimental}

\subsection{Catalyst}

The catalyst used was a silica-supported nickel catalyst prepared by the precipitation method in which nickel carbonate was precipitated on silica gel from an aqueous solution of nickel nitrate by addition of an aqueous solution of ammonium carbonate. The catalyst prepared in this way was calcined at $450^{\circ} \mathrm{C}$ for $2 \mathrm{hr}$. The nickel content was about $20 \mathrm{wt} \%$.

\subsection{Apparatus and Procedure}

The experiments were carried out in a flow system at atmospheric presure. The schematic flow diagram is shown in Fig. 1. The reactor was constructed from a $16 \mathrm{~mm}$ inside diameter 


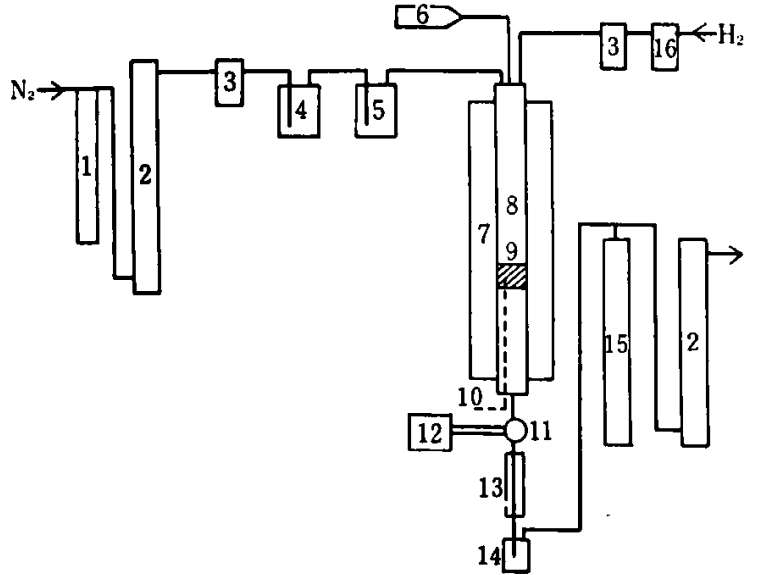

1. Orifice-type flow meter 9. Catalyst bed

2. Soap film flow meter 10. Thermocouple

3. Drier (Calcium chloride) 11. Six-ways cock

4. Saturater (Hydrocarbon) 12. Gas chromatography

5. Saturater (Steam) 13. Condenser

6. Microfeeder 14. Trap

7. Electric furnace 15. Effluent gas holder

8. Reactor 16. Deoxo unit

Fig. 1 Schematic Diagram of Reaction Apparatus

silica tube of $700 \mathrm{~mm}$ length. The temperature of the catalyst bed was measured by an alumelchromel thermocouple. Water was fed quantitatively into the reactor from a steam-saturater with carrier nitrogen. Hydrocarbons were fed from a saturater or a microfeeder. The flow velocity of carrier nitrogen was measured by an orifice type flow meter. Prior to each run, the catalyst was reduced in a hydrogen stream at $710^{\circ} \mathrm{C}$ at atmospheric pressure for $3 \mathrm{hr}$. After reduction, the catalyst was cooled to the reaction temperature in a hydrogen stream. The feed hydrocarbon and steam were passed through the catalyst bed which was maintained at the desired reaction temperature. The reactor effluent was analyzed 10 minutes after the start by gas chromatography and by means of absorption with an aqueous solution of potassium hydroxide. The analysis by gas chromatography was made in two ways; (1) Aromatic hydrocarbons were analyzed by P.E.G. $20 \mathrm{M}$. column at $130^{\circ} \mathrm{C}$ using hydrogen as the carrier gas. (2) $\mathrm{H}_{2}$, $\mathrm{N}_{2}, \mathrm{CH}_{4}$ and $\mathrm{CO}$ were analyzed by Molecular Sieve $5 \mathrm{~A}$ at room temperature using argon as the carrier gas.

\subsection{Materials}

Hydrocarbons used in the present study were commercially available (Wako Junyaku Co.) at better than $99 \%$ purity. Water was distilled before use. Cylinder hydrogen was purified by passing through a deoxo unit and a calcium chloride drier. Cylinder nitrogen was dried by calcium chloride.

\section{Results and Discussions}

\subsection{Benzene-Steam Reaction}

\subsubsection{Products Distribution}

The main products in the benzene-steam reaction in the temperature range of $370 \sim 430^{\circ} \mathrm{C}$ were hydrogen, carbon dioxide and methane. Carbon monoxide was almost negligible and partially decomposed hydrocarbons were not detectable in the products. From a carbon balance, deposition of carboneous materials on the surface of the catalysts was also negligible. Products distribution at 370 and $430^{\circ} \mathrm{C}$ are shown
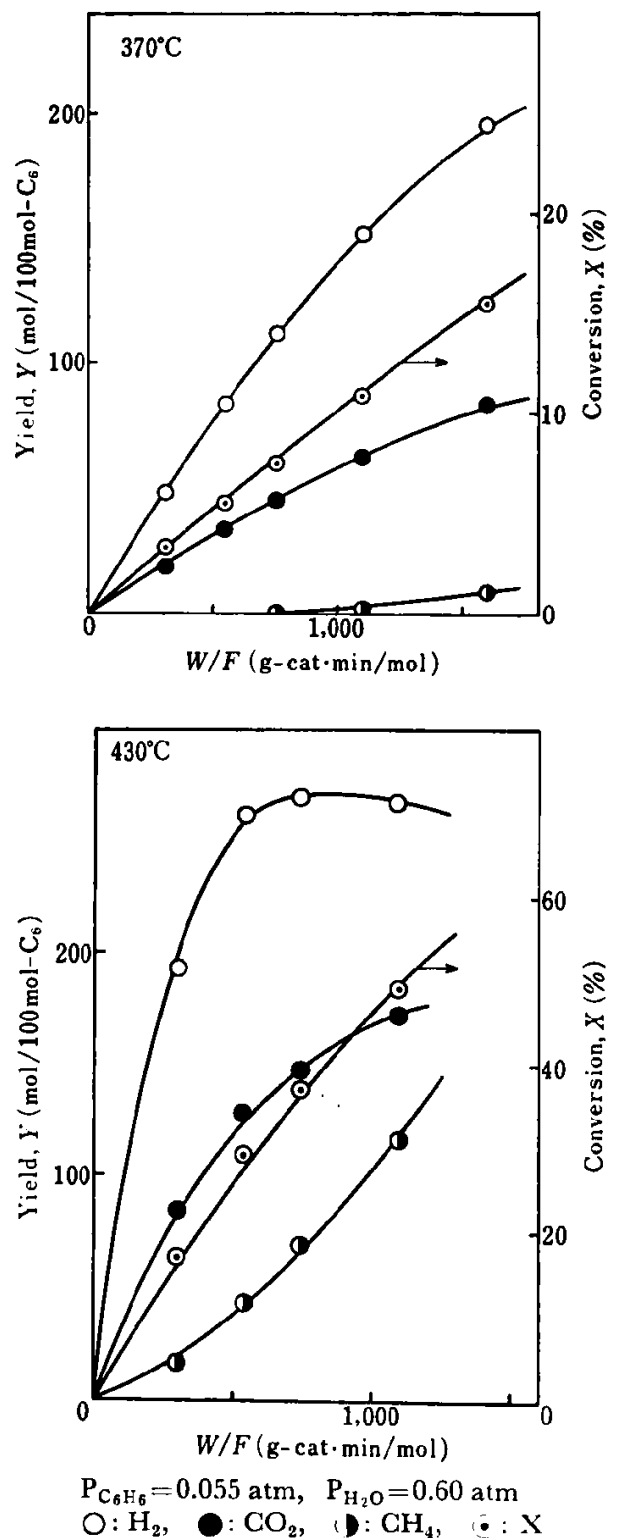

Fig. 2 Products Distribution for Benzene-Steam Reaction 
in Fig. 2, where $W$ is the weight of catalyst in grams and $F$ is the feed ratc of benzene to the reactor in $\mathrm{mol} / \mathrm{min}$. Though the yield of methane is small at the initial stage of reaction, it increases as the reaction advances. On the contrary, the yield of hydrogen begins to decrease at high conversion.

The reactions that might occur on the catalyst are represented by the following equations:

$$
\text { or } \begin{array}{ll}
\mathrm{C}_{6} \mathrm{H}_{6}+6 \mathrm{H}_{2} \mathrm{O} \rightleftharpoons 6 \mathrm{CO}+9 \mathrm{H}_{2} \\
\mathrm{CO}+12 \mathrm{H}_{2} \mathrm{O} \rightleftharpoons 6 \mathrm{HOO}_{2}+15 \mathrm{H}_{2} \\
\mathrm{CO}+3 \mathrm{CO}_{2} \rightleftharpoons \mathrm{H}_{2} \rightleftharpoons \mathrm{CH}_{4}+\mathrm{H}_{2} \mathrm{O}
\end{array}
$$

In calculating the equilibriuri value in these reactions, two assumptions have been made as follows:

(a) The deposition of carbon is kinetically slow and any carbon formed is consumed in the reaction of $\mathrm{C}+\mathrm{H}_{2} \mathrm{O} \rightarrow \mathrm{CO}+\mathrm{H}_{2}$.

(b) Eq. (3) and (4) are established over all conversion under present experimental condition.

The estimated product distributions are obtained in the same way as described in the previous report ${ }^{2)}$ and are shown in Fig. 3 in comparison with experimental results. The experimental points follow the estimated distribution curve at lower conversion, but deviate from it at higher conversion, i.e. the yield of methane is less and the yield of carbon dioxide is more than the estimated value. However, the deviation is reduced as reaction temperature increases. This could be explained on the supposition that methanation of carbon monoxide (eq. (4)), which is initially formed by benzene-steam reaction, is slow in comparison with the conversion of carbon monoxide (eq. (3)). As methanation proceeds more rapidly at higher temperature, experimental points approach the estimated distribution curve.

\subsubsection{Effects of the Partial Pressures of Reactants on Benzene-Steam Reaction}

Fig. 4 shows effects of the partial pressure of benzene or steam on the initial rate of the reaction at $370^{\circ} \mathrm{C}$. The reaction is zero order with respect to benzene and approximately first order with respect to steam. As these results are similar to that obtained in paraffins-steam reactions ${ }^{\mathrm{l}}$, it is suggested that benzene-steam reaction proceeds under the same scheme as paraffins-steam reactions.
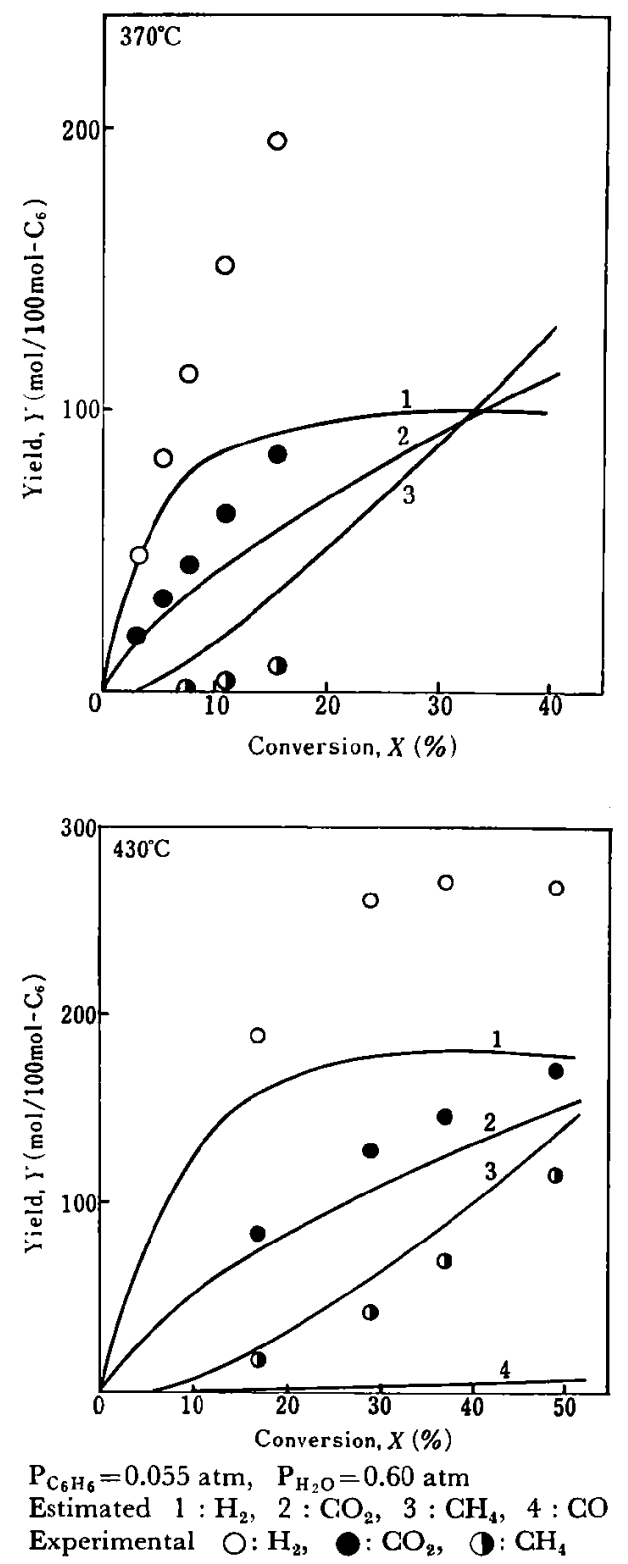

Fig. 3 Estimated and Experimental Yields for BenzeneSteam Reaction

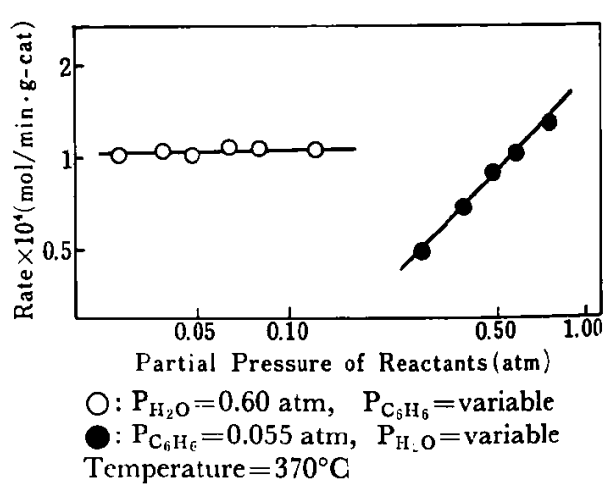

Fig. 4 Effects of the Partial Pressure of Reactants on the Rate of Benzene-Steam Reaction

Bulletin of The Japan Petroleum Institute 
adsorbed species (A) adsorbed species (B)

$$
\begin{aligned}
& \mathrm{C}_{6} \mathrm{H}_{6} \rightleftharpoons\left(\mathrm{C}_{6} \mathrm{H}_{\mathrm{x}}\right)_{\text {ad }} \longrightarrow\left(\mathrm{C}_{y} \mathrm{H}_{2}\right)_{\text {ad }} \\
& \downarrow \mathrm{H}_{2} \mathrm{O} \\
& \text { Products }
\end{aligned}
$$

It is proposed that benzene is initially adsorbed (perhaps dissociatively) and the adsorbed species (A) may convert to the adsorbed species (B) with rupture of $\mathrm{C}-\mathrm{C}$ bond. It is further proposed that the rate determining step is the surface reaction of the adsorbed species (B) either with water from the gaseous phase or with water weakly adsorbed on the catalyst.

\subsection{Toluene-Steam Reaction}

\subsubsection{Products Distribution}
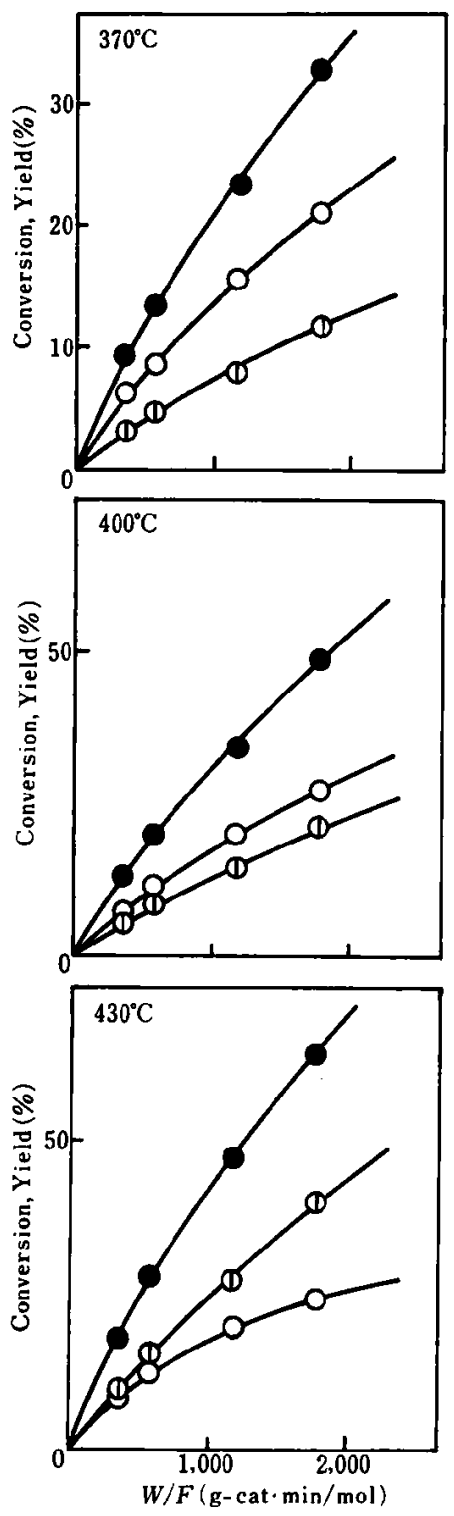

$P_{\mathrm{C}_{7}}=0.07 \mathrm{~atm}, \mathbf{P}_{\mathrm{H}_{2} \mathrm{O}}=0.50 \mathrm{~atm}$
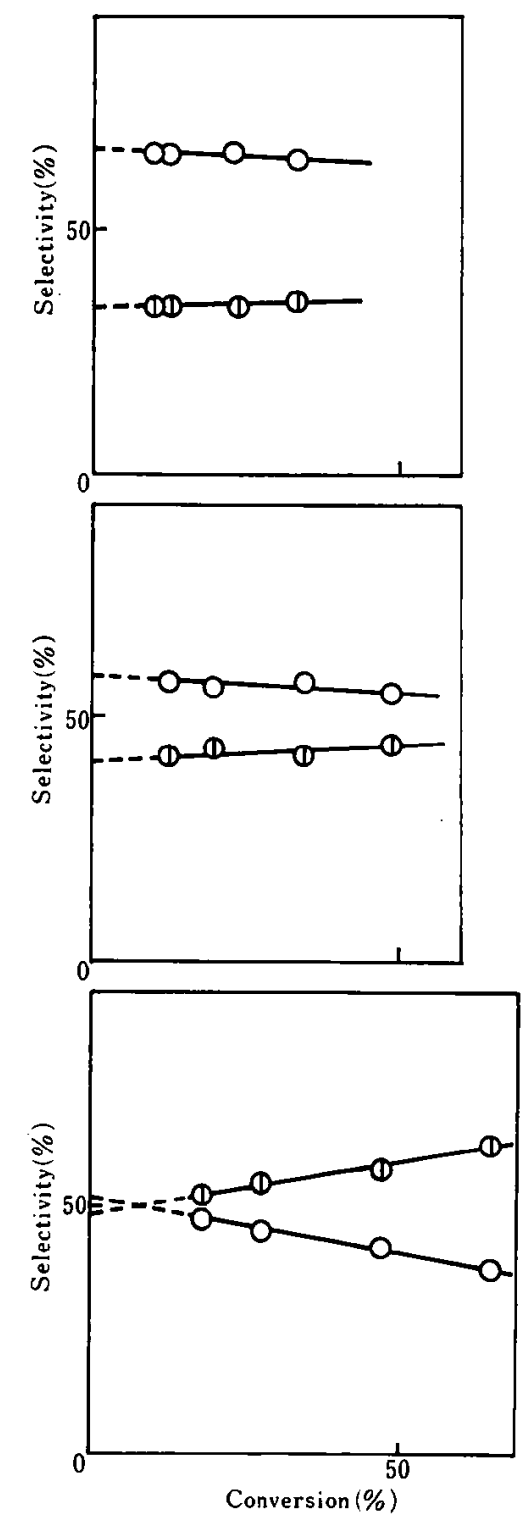

: Conversion of toluene, $\bigcirc$ : Demethylation, (?: Ring breakdown

Fig. 5 Toluene-Steam Reaction 
of toluene are determined as follows:

Yicld of demethylation

$$
Y_{D M}(\%)=Y_{B}
$$

Yield of ring breakdown

$$
Y_{R B}(\%)=\left(Y_{\mathrm{CO}_{2}+\mathrm{CH}_{4}}-Y_{B}\right) / 7
$$

Conversion of toluene

$$
X_{T}(\%)=Y_{D M}+Y_{R B}
$$

Fig. 5 shows the relation of $W / F$ with yield and conversion, and of selectivity with conversion, where

Selectivity for demethylation

$$
S_{D M}(\%)=\left(Y_{D M} / X_{T}\right) \times 100
$$

Selectivity for ring breakdown

$$
S_{R B}(\%)=\left(Y_{R B} / X_{T}\right) \times 100
$$

In Fig. 5, the selectivity of ring breakdown increases as the reaction advances, especially at high temperature. This implies that the benzene formed by demethylation further reacts with steam. Since the initial selectivities for demethylation and ring breakdown which are estimated by extrapolating selectivities to zero conversion are not zero, it is suggested that both demethylation and ring breakdown occur even at the initial stage of the reaction. Therefore, the following reaction path is supposed.

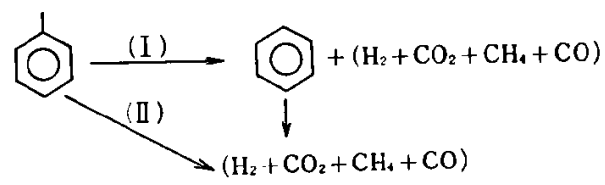

With a rise in temperature, the initial selectivity for demethylation (path (I)) decreases and that for ring breakdown (path (II)) increases. This suggests that the activation energy of demethylation is smaller than that of ring breakdown.

\subsubsection{Effects of Partial Pressures of Reac- tants on Toluene-Steam Reaction}

Fig. 6 and 7 show the effects of the partial pressure of toluene or steam on the reaction at $400^{\circ} \mathrm{C}$. As is shown, ring breakdown is nearly zero order with respect to toluene, and approximately first order with respect to steam. On the other hand, the rate of demethylation depends on the partial pressure of toluene and steam at lower partial pressure, but does not at higher partial pressure. These results suggest that the adsorbed state of toluene for ring breakdown differs from that for demethylation. That is, the adsorbed position of toluene would be methyl group for demethylation ${ }^{4}$, and benzene ring for ring breakdown. The results for demethylation of toluene in Fig. 6 and 7 could be explained

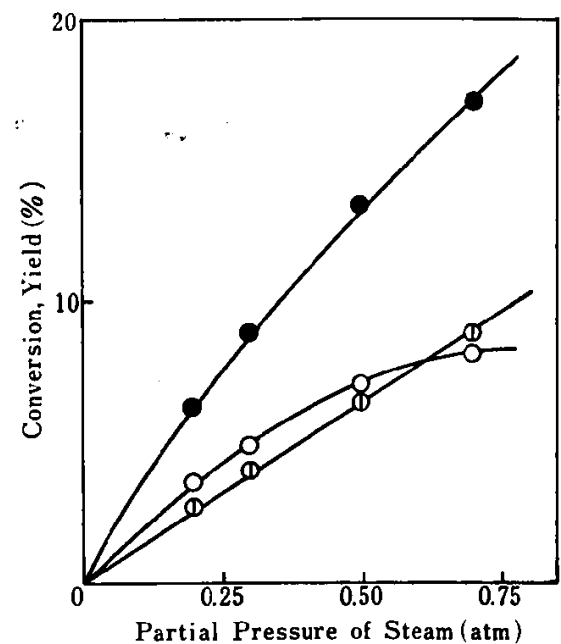

$\mathrm{P}_{\mathrm{C}_{7}}=0.07$ atm, Temperature $=400^{\circ} \mathrm{C}$

: Conversion of toluene, $\mathrm{O}$ : Demethylation (1): Ring breakdown

Fig. 6 Effects of the Partial Pressure of Steam on Toluene-Steam Reaction

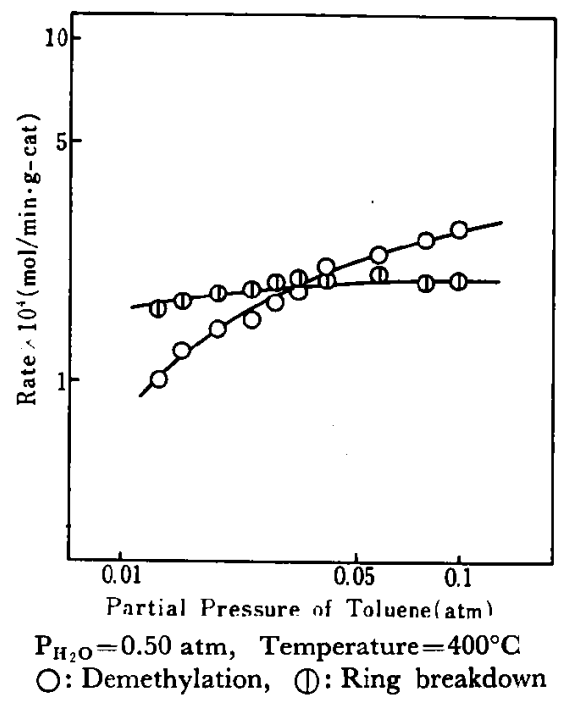

Fig. 7 Effects of the Partial Pressure of Toluene on Toluene-Steam Reaction

on the supposition that the reaction of adsorbed species with steam is considerably fast, and that the catalyst surface is not completely filled with adsorbed species. On the other hand, the scheme of ring breakdown may be similar to that of the benzene-steam reaction, and also as to adsorbed species.

\subsection{Alkylbenzenes-Steam Reactions}

Table 1 shows the products of the reactions of several alkylbenzenes with steam in the temperature range of $370 \sim 430^{\circ} \mathrm{C}$. In any case, the yield of carbon monoxide and carbon deposition were negligible, and there was no isomerization of alkylbenzenes. 
Alkylbenzenes with Steam over a Silica-supported Nickel Catalyst

Table 1 Products for Alkylbenzenes-Steam Reactions

\begin{tabular}{l|l|l}
\hline \multicolumn{1}{c|}{ Reactants } & Aromatic Hydrocarbons & Other Products \\
\hline $\begin{array}{l}\text { o-Xylene } \\
m \text {-Xylene } \\
p \text {-Xylene } \\
\text { Ethylbenzene }\end{array}$ & $\begin{array}{l}\text { Benzene } \\
\text { Toluene }\end{array}$ & $\begin{array}{l}\mathrm{H}_{2} \\
\mathrm{CO}_{2}\end{array}$ \\
\hline Cumene & $\begin{array}{l}\text { Benzene, Toluene } \\
\text { Ethylbenzene }\end{array}$ & $(\mathrm{CO})$ \\
\hline Pseudocumene & $\begin{array}{l}\text { Benzene, Toluene } \\
\text { Xylene Isomers }\end{array}$ & \\
&
\end{tabular}

Both dealkylation (demethylation) and ring breakdown occured in any case, and these yields were determined as follows;

Yield of dealkylation $\left(Y_{D A}\right)$

for xylene isomers and ethylbenzene

$$
Y_{D A}=Y_{T}+Y_{B}
$$

for pseudocumene

$$
Y_{D A}=Y_{X}+Y_{T}+Y_{B}
$$

for cumene

$$
Y_{D A}=Y_{E B}+Y_{T}+Y_{B}
$$

Yield of ring breakdown $\left(Y_{R B}\right)$

for xylene isomers and ethylbenzene

$Y_{R B}=\left[Y_{G}-\left(Y_{T}+2 Y_{B}\right)\right] / 8$

for pseudocumene

$$
Y_{R B}=\left[Y_{G}-\left(Y_{X}+2 Y_{T}+3 Y_{B}\right)\right] / 9
$$

for cumene

$$
Y_{R B}=\left[Y_{G}-\left(Y_{E B}+2 Y_{T}+3 Y_{B}\right)\right] / 9
$$

Total conversion

$$
X=Y_{D A}+Y_{R B}
$$

where $Y_{B}, Y_{T}, Y_{X}$ and $Y_{E B}$ are the yields of benzene, toluene, xylenes and ethylbenzene respectively, and $Y_{G}$ is the total yield of carbon dioxide and methane. The selectivities are determined in the same way as described in 3.2.1 and the initial selectivities for the products in each reaction are obtained by linear extrapolation.

\subsubsection{Polymethylbenzenes-Steam Reactions}

Results obtained in the reaction of 0 -xylene, $m$-xylene, $p$-xylene and pseudocumene with steam are shown in Fig. 8 to 11 and Table 2. A comparison of the results for xylene isomers indicates the following facts.

(i) The sequence of the rate of reaction is $p$-xylene $\geq m$-xylene $>0$-xylene

(ii) The sequence of the rate of demethylation is

$p$-xylene $\geq m$-xylene $>0$-xylene

and that of ring breakdown is

$o$-xylene $z m$-xylene $\approx p$-xylene

(iii) The sequence of selectivity for de-
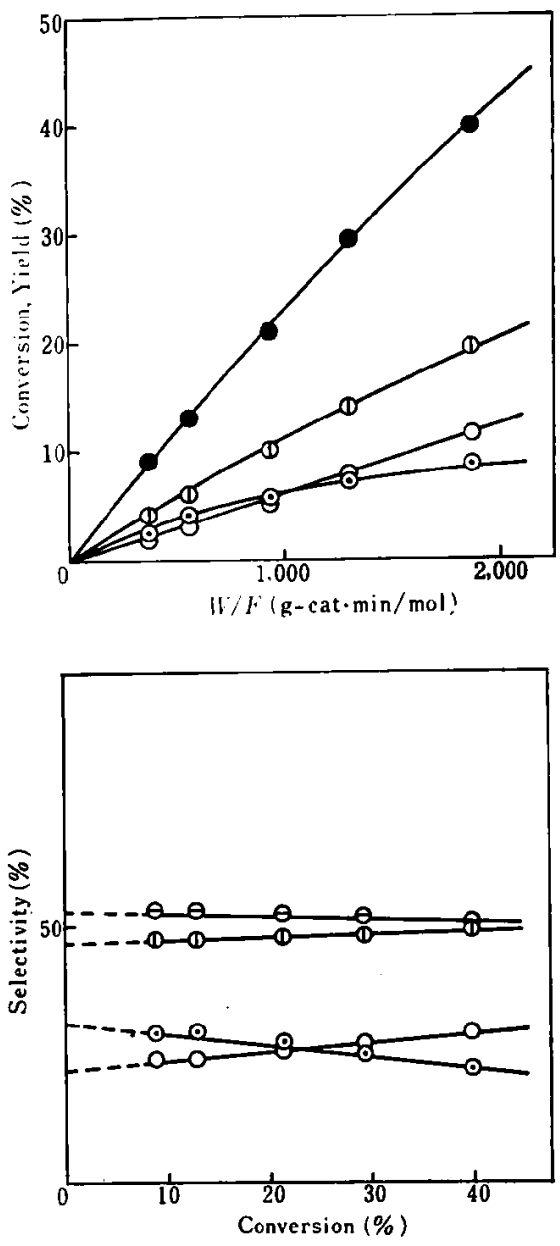

$P_{\mathrm{C}_{s}}=0.05 \mathrm{~atm}, \mathrm{P}_{\mathrm{H}, \mathrm{O}}=0.55 \mathrm{~atm}$, Temperature $=400^{\circ} \mathrm{C}$ : Conversion of o-xylene, (1): Ring breakdown, $\odot$ : Toluene, $\bigcirc$ : Benzene, $\ominus$ : Sum of dealkylation

Fig. 8 o-Xylene-Steam Reaction

methylation is

$p$-xylene $z m$-xylene $>$ o-xylene and that for ring breakdown is inverse.

(iv) Benzene and toluene are the initial products of demethylation in the o-xylenesteam reaction, and toluene is the only initial product of demethylation in $m$-xylenesteam and $p$-xylene-steam reactions.

(i), (ii) and (iii) lead to the assumption that both the total rate of reaction and the selectivity for demethylation are related to the rate of demethylation. The fact (iv) implies that the reaction path for 0 -xlyene differs from that for $m$-xylene or $p$-xylene. Though toluene and benzene are products of demethylation in the reaction of $m$-xylene or $p$-xylene with steam, toluene is the only product of demethylation at the initial stage of the reaction. This fact suggests that xylene reacts with steam at one methyl group to form toluene, and subsequently the

Volume 14, No. 1, May 1972 

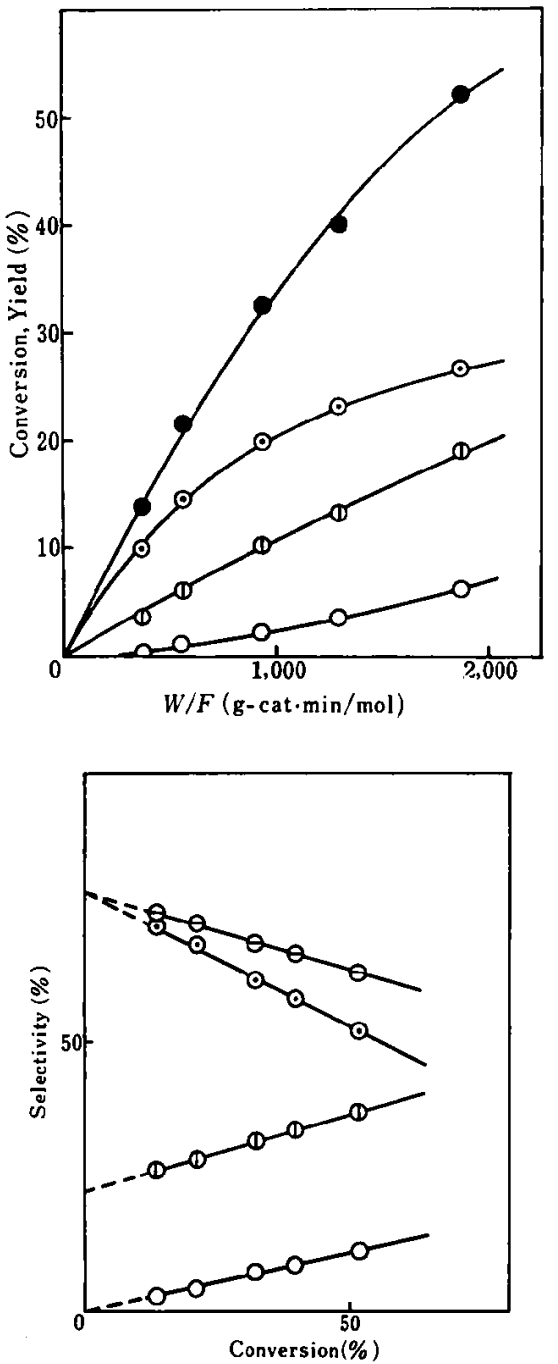

$P_{\mathrm{C}_{8}}=0.05 \mathrm{~atm}, \mathrm{P}_{\mathrm{H}_{2} \mathrm{O}}=0.55 \mathrm{~atm}$, Temperature $=400^{\circ} \mathrm{C}$ : Conversion of $m$-xylene, (1): Ring breakdown, : Toluene, 0 : Benzene, $\theta$ : Sum of dealkylation

Fig. $9 m$-Xylene-Steam Reaction

toluene formed reacts with steam to form benzene as the final demethylation product. On the other hand, both benzene and toluene were formed at the beginning of the o-xylene-steam reaction. This implies that two kinds of demethylation forming toluene or benzene might occur simultaneously. On the basis of these considerations, the main reaction paths of demethylation of xylene isomers are suggested as follows:

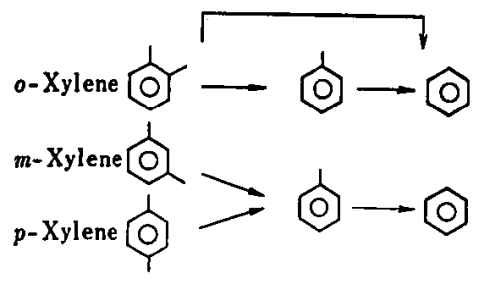

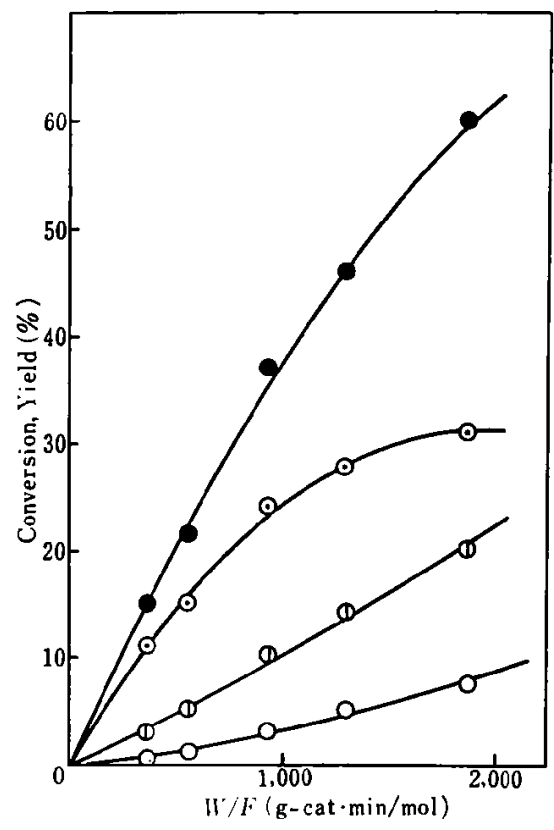

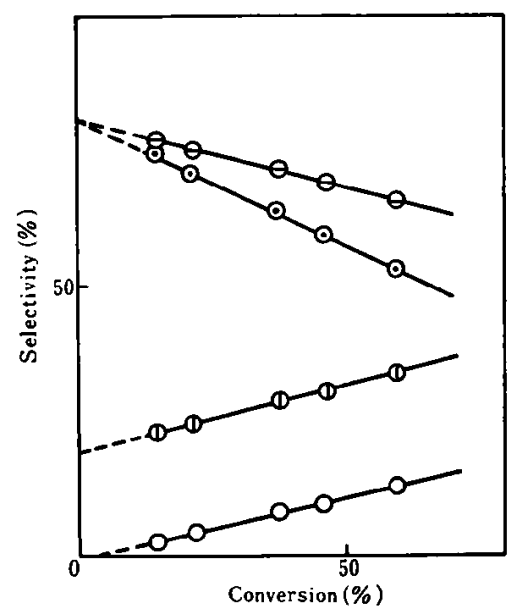

$\mathrm{P}_{\mathrm{C}_{\mathrm{B}}}=0.05 \mathrm{~atm}, \mathrm{P}_{\mathrm{H}_{2} \mathrm{O}}=0.55 \mathrm{~atm}$, Temperature $=400^{\circ} \mathrm{C}$ : Conversion of p-xylene, $\Phi:$ Ring breakdown (6): Toluene, $O$ : Benzene, $\Theta$ : Sum of dealkylation

Fig. 10 p-Xylene-Steam Reaction

From the extrapolation of data of the pseudocumene-steam reaction and the results of xylene isomers, the reaction path of demethylation of pseudocumene is suggested as follows:

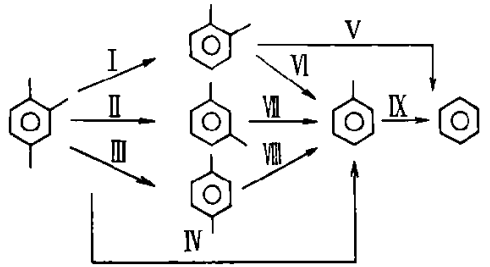

The sequence of the rate of reaction steps for this proposed path is I $>$ II + III $>$ IV for pseudocumene-steam reaction, and $\mathrm{VIII} \geq \mathrm{VII}>\mathrm{VI}$ for xylene isomers-steam reactions. As the 

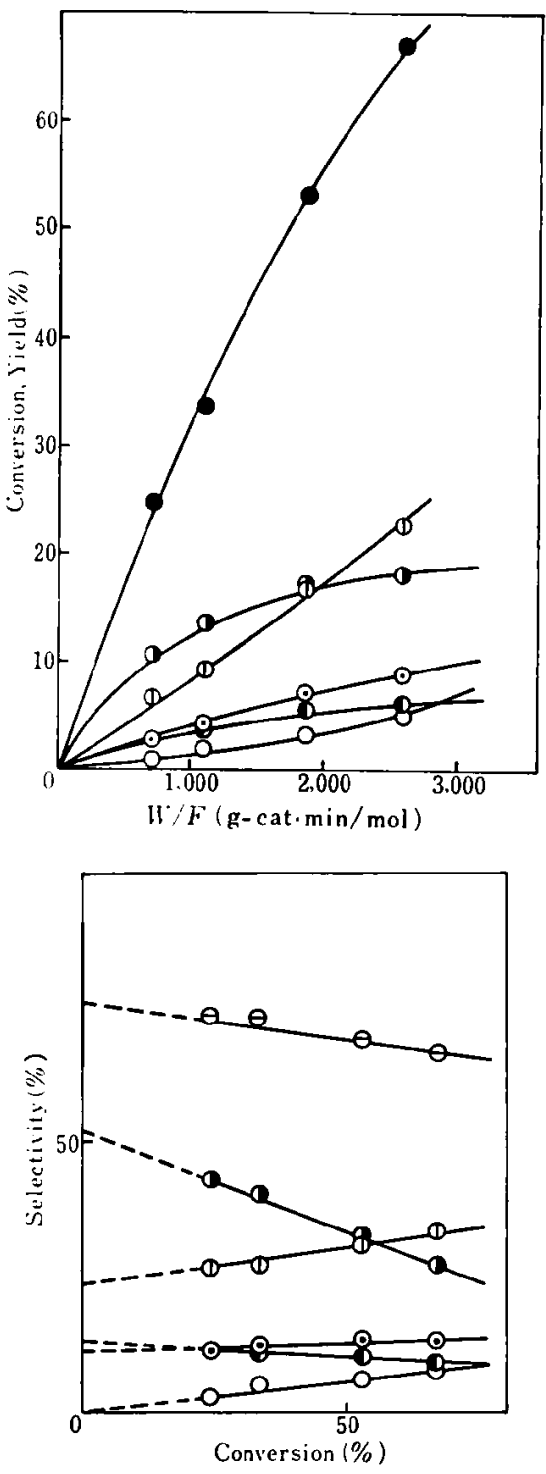

$P_{C_{9}}=0.023 \mathrm{~atm}, P_{\mathrm{H}_{2} \mathrm{O}}=0.55 \mathrm{~atm}$, Temperature $=400^{\circ} \mathrm{C}$ 0 : Conversion of pseudocumene, $\tau$ : Ring breakdown, (1: $o$-Xylene, O: $m$-, $p$-Xylene, Toluene, $O$ : Benzene, $\Theta$ : Sum of dealkylation

Fig. 11 Pseudocumenc-Steam Reaction

yield of $o$-xylene is greatest in the pseudocumenesteam reaction, a methyl group in the 4-position on the ring would be split most easily. A methyl group in the 1 or 2-position seems to be split moderately, but simultaneous splitting of two methyl groups appears to be difficult.

Table 3 shows the relative rates of demethylation of polymethylbenzenes. The relative rates are related to the combined position of methyl groups, that is, the rate of demethylation diminishes if the subsequent methyl group occupies the ortho position relative to the preceding ones, and increases if the subsequent methyl group occupies the meta or para posi-
Table 2 Initial Selectivity for the Products in Polymethylbenzenes-Steam Reactions

\begin{tabular}{|c|c|c|c|c|}
\hline \multirow{2}{*}{ Reactants } & \multirow{2}{*}{ Products } & \multicolumn{3}{|c|}{ Initial Selectivity $(\%)$} \\
\hline & & $370^{\circ} \mathrm{C}$ & $400^{\circ} \mathrm{C}$ & $430^{\circ} \mathrm{C}$ \\
\hline Toluene & $\begin{array}{l}\text { Benzene } \\
\text { Ring Breakdown }\end{array}$ & $\begin{array}{l}66 \\
34\end{array}$ & $\begin{array}{l}59 \\
41\end{array}$ & $\begin{array}{l}49 \\
51\end{array}$ \\
\hline$o-$ Xylene & $\begin{array}{l}\text { Benzene } \\
\text { Toluene } \\
\text { Ring Breakdown }\end{array}$ & $\begin{array}{l}20 \\
38 \\
42\end{array}$ & $\begin{array}{l}22 \\
31 \\
47\end{array}$ & $\begin{array}{l}21 \\
26 \\
53\end{array}$ \\
\hline$m$-Xylene & $\begin{array}{l}\text { Benzene } \\
\text { Toluene } \\
\text { Ring Breakdown }\end{array}$ & $\begin{array}{l}\overline{84} \\
16\end{array}$ & $\begin{array}{l}-78 \\
22\end{array}$ & $\begin{array}{l}\overline{72} \\
28\end{array}$ \\
\hline$p$-Xylene & $\begin{array}{l}\text { Benzene } \\
\text { Toluene } \\
\text { Ring Breakdown }\end{array}$ & $\begin{array}{l}\overline{88} \\
12\end{array}$ & $\begin{array}{l}-\overline{81} \\
19\end{array}$ & $\begin{array}{l}- \\
76 \\
24\end{array}$ \\
\hline Pseudocumene & $\begin{array}{l}\text { Benzene } \\
\text { Toluene } \\
o-X y l e n e \\
m-\text { and } p-X y l e n e \\
\text { Ring Breakdown }\end{array}$ & $\begin{array}{l}-11 \\
58 \\
14 \\
17\end{array}$ & $\begin{array}{l}-11 \\
52 \\
13 \\
24\end{array}$ & $\begin{array}{l}-11 \\
48 \\
11 \\
30\end{array}$ \\
\hline
\end{tabular}

Table 3 Relative Rate of Demethylation in Polymethylbenzenes-Steam Reactions

\begin{tabular}{l|c}
\hline \multicolumn{1}{c|}{ Reactant } & Relative Rate of Demethylation \\
\hline Toluene & 1.00 \\
$o$-Xylene & 0.62 \\
$m$-Xylene & 1.41 \\
$p$-Xylene & 1.61 \\
Pseudocumene & 1.16 \\
\hline
\end{tabular}

tion. Demethylation of polymethylbenzenes occurs by the adsorption of hydrocarbons at the methyl group on the catalyst ${ }^{4}$, and the decrease in demethylation rate when the subsequent methyl group occupies the ortho position is caused by stereo hindrance of neighbouring methyl groups ${ }^{8}$. But the increase in the demethylation rate when the subsequent methyl group occupies the meta or para position can not be explained on the basis of these suggestions. The electronic distribution in polymethyl benzenes varies with the position of the methyl group and it may influence the reaction path. (There is no information available which describes these circumstances.)

From the observation of simultaneous splitting of two methyl groups in the $o$-xylene-steam or pseudocumene-steam reaction, it is supposed that these polymethylbenzenes are adsorbed at two neighbouring methyl groups.

\subsubsection{Ethylbenzene-Steam and Cumene- Steam Reaction}

Fig. 12, 13 and Table 4 show the results obtained in the reaction of ethylbenzene or cumene with steam. From these results, the reaction 
path of dealkylation is suggested as follows:

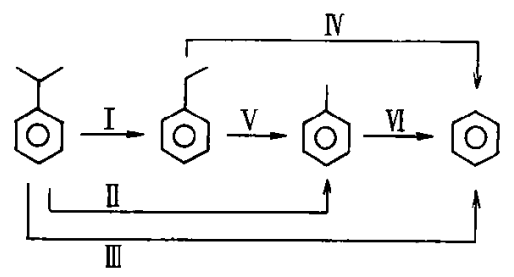

The sequence of the rate of reaction steps is III $>$ II $>$ I for the cumene-steam reaction, and IV $>V$ for the ethylbenzene-steam reaction. Furthermore, the above-mentioned results reveal the following phenomena.

(i) In dealkylation of ethylbenzene or cumene,
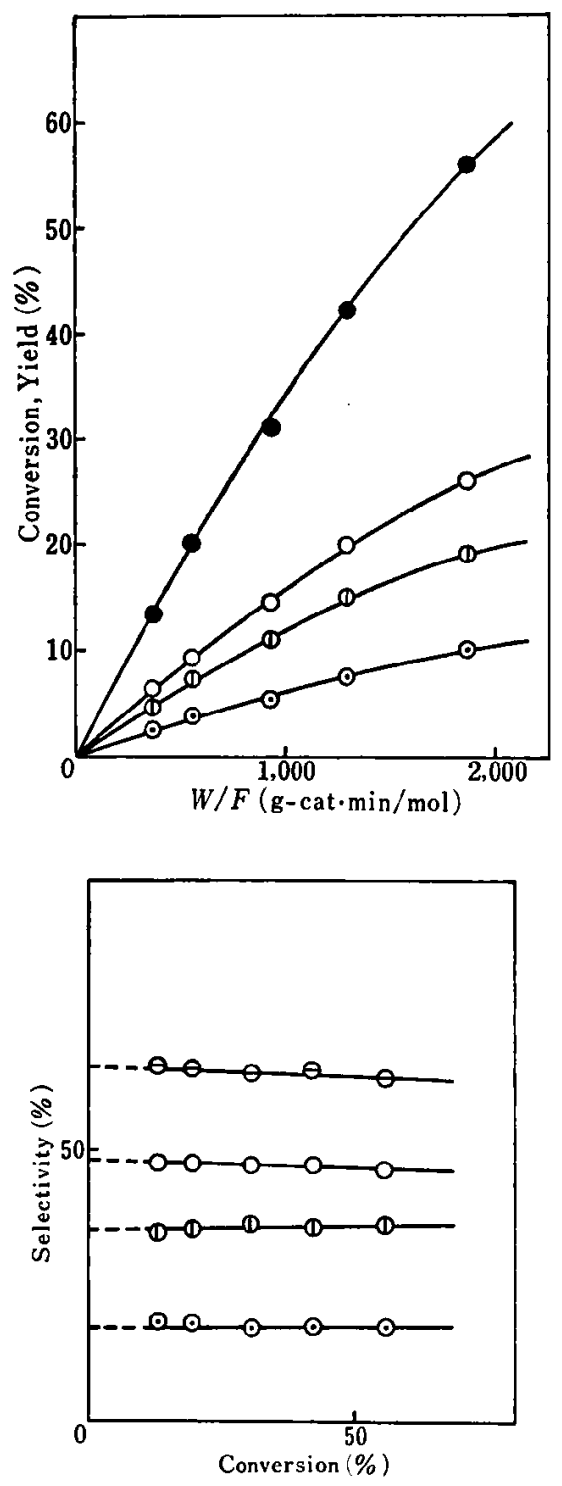

$\mathrm{P}_{\mathrm{C}_{8}}=0.05 \mathrm{~atm}, \quad \mathrm{P}_{\mathrm{H}_{2} \mathrm{O}}=0.55 \mathrm{~atm}$, Temperature $=400^{\circ} \mathrm{C}$ : Conversion of ethylbenzene, $\Phi$ : Ring breakdown, 6: Toluene, $\bigcirc$ : Benzene, $\ominus$ : Sum of dealkylation Fig. 12 Ethylbenzene-Steam Reaction splitting of the methyl group occurs most easily at the carbon atom connected to the benzene ring.

(ii) The sequence of the rate of dealkylation is ethylbenzene $>$ cumene
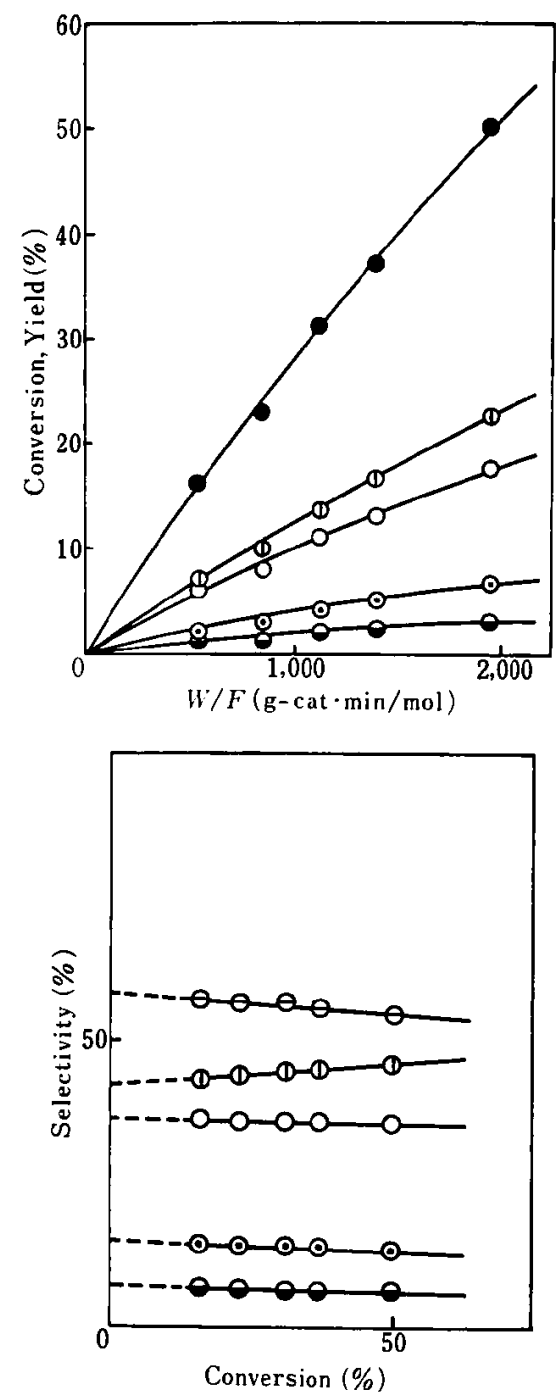

$\mathrm{P}_{\mathrm{C}_{9}}=0.04 \mathrm{~atm}, \quad \mathrm{P}_{\mathrm{H}_{2} \mathrm{O}}=0.56 \mathrm{~atm}$, Temperature $=400^{\circ} \mathrm{C}$ : Conversion of cumene, D: Ring breakdown, $\odot$ : Ethylbenzene $\odot$ : Toluene, $\bigcirc$ : Benzene, $\theta$ : Sum of dealkylation

Fig. 13 Cumene-Steam Reaction

Table 4 Initial Selectivity for the Products in Ethylbenzene-Steam and Cumene-Steam Reaction

\begin{tabular}{l|l|ccr}
\hline \multirow{2}{*}{ Reactant } & \multirow{2}{*}{ Products } & \multicolumn{3}{|c}{ Initial Selectivity (\%) } \\
\cline { 3 - 5 } & & $370^{\circ} \mathrm{C}$ & $400^{\circ} \mathrm{C}$ & $430^{\circ} \mathrm{C}$ \\
\hline \multirow{2}{*}{ Ethylbenzene } & Benzene & 49 & 48 & 43 \\
& Toluene & 21 & 17 & 16 \\
& Ring Breakdown & 30 & 35 & 41 \\
\hline \multirow{2}{*}{ Cumene } & Benzene & 40 & 36 & 31 \\
& Toluene & 18 & 15 & 13 \\
& Ethylbenzene & 7 & 7 & 7 \\
& Ring Breakdown & 35 & 42 & 49 \\
\hline
\end{tabular}

Bulletin of The Japan Petroleum Institute 
It is supposed that these alkylbenzenes are adsorbed on nickel catalyst at one or two carbon atoms of the alkyl group, and the structure of the alkyl group may influence the adsorption state and the reaction rate of these alkylbenzenes.

\subsubsection{Reactivity for Ring Breakdown}

The discussion up to this point has been focussed primarily on dealkylation. Now ring breakdown of aromatic hydrocarbons will be discussed. From the results described, the sequence of the rate of ring breakdown is, benzene $>$ toluene $>$ ethylbenzene $>$ cumene $>$ o-xylene $>m$-xylene $z p$-xylene $\geq$ pseudocumene As is obvious, the rate of ring breakdown decreases with an increase in the number of substituted alkyl groups. It is considered that, to cause ring breakdown, aromatic hydrocarbons should be adsorbed on the catalyst not by alkyl group but by benzene ring, and the adsorbed species for ring breakdown should be different from those for dealkylation. According to these considerations, it may be supposed that the surface sites on which demethylation occurs differ from those on which ring breakdown occurs.

\section{References}

1) Saito, M., Tokuno, M., Amano, I., Morita, Y., Kogyo Kagaku Zasshi (J. Chem. Soc. Japan, Ind. Chem. Sect.), 73, 2405 (1970).

2) Morita, Y., Saito, M., Tokuno, M., Memoirs of the School of Science \& Engineering, Waseda Univ., No. 34, 125 (1970).

3) Tokuno, M., Iwaki, T., Saito, M., Morita, Y., Ann. Meeting Chem. Soc. Japan, 24th Osaka, Preprints of Paper, No. 4, 1945 (1971).

4) Balandin, A. A., Maslyanskii, G. N., Slovokhotova, T. A., Rabinovich, G. L., 7th World Petroleum Congress, 5, 121 (1967).

5) Igarashi, A., Ogino, Y., Bull. Japan Petrol. Inst, 12, $112(1970)$.

6) Tsuchiya, M., Igarashi, A., Ogino, Y., J. Japan Petrol. Inst., 13, (8), 639 (1970).

7) Tsuchiya, M., Igarashi, A., Ogino, Y., ibid., 13, (8), 643 (1970).

8) Maslyanskii, G. N., Rabinovich, G. L., Brisker, K. L., Petrol. Chem., 4, 124 (1965). 